\title{
Height and Weight Adjusted Dose versus Fixed Dose of Bupivacaine for Spinal Anaesthesia for Caesarean
}

\author{
Authors \\ Dr Santhi K S ${ }^{1}$, Dr Manu $S^{2}$ \\ ${ }^{1}$ Associate Professor in Anaesthesia, Govt Medical College, Kottayam \\ ${ }^{2}$ Dept of Anaesthesiology, Govt Medical College, Kottayam
}

\begin{abstract}
Spinal Anaesthesia is the preferred choice of anaesthesia for caesarean sections. It avoids the risks associated with general anaesthesia like the risk of aspiration, incidence of difficult airway etc. However it is not without problems. At present a variety of dosage regimens are employed irrespective of patient characteristics. This may result in unwarranted hypotension in some cases due to overdosing and inadequate anaesthesia in some other cases due to under dosing. In this study we compared two dosage regimens for spinal anaesthesia for elective caesarean sections. One was the fixed dosage regimen and the other one, an adjusted dosage regimen based on the patient's height and weight. It was found that the adjusted dosage regimen significantly reduced the incidence of side effects due to overdosing like hypotension without compromising on the efficacy of intraoperative anaesthesia
\end{abstract}

Keywords: Spinal Anaesthesia, Caesarean Sections, Bupivacaine.

\section{Introduction}

Caesarean sections are most commonly done under spinal anaesthesia. It may also be performed under general anaesthesia or under epidural block. However general anaesthesia is associated with increased risk for aspiration, chances of difficult airway etc due to the so called dynamic airway of pregnancy etc. Epidural anaesthesia is technically more complicated and requires higher dose of the drugs and significant delay in the onset time for analgesia. So the preferred technique for caesarean section is spinal anaesthesia.

However spinal anaesthesia in caesarean section has its own problems. It may lead to unwanted side effects like hypotension and bradycardia due to increased sensitivity of the parturient to local anaesthetic drugs. Dosage regimens for spinal anaesthesia in caesarean sections can lead to inadequate analgesia in some cases due to under dosing and may cause side effects like hypotension and bradycardia in some other cases due to overdosing. In this study we compared two dosage regimens for spinal anaesthesia in caesarean section. One was a fixed dosage regimen in which the parturients were given a fixed dose of $2 \mathrm{ml}$ of $0.5 \%$ bupivacaine .The other group were given a height and weight based adjusted dose of bupivacaine \{Reference: Harten JM, Boyne I, Hannah P, Varveris D, Brown A. Effect of a height and weight adjusted dose of local anesthetic for spinal anesthetic for elective caesarean $\}$. We compared the adequacy and side effects in both groups. 


\section{JMSCR Vol||05||Issue||12||Page 32130-32141||December}

\section{Objectives}

To test whether adjusting the dose of intrathecal bupivacaine according to the patient's height and weight would provide adequate surgical anaesthesia for elective caesarean sections, without producing significant adverse effects, compared to a fixed dosage regimen.

\section{Materials and Methods}

A comparative study involving 150 parturients were conducted in a tertiary care teaching hospital after the approval by the ethics committee of the institution.

Inclusion criteria: Pregnant women of age 20-40 years undergoing elective caesarean section, and having weight between 40-100 kg

Exclusion criteria: 1) Those undergoing emergency caesarean section, 2)Multiple pregnancy, 3)Associated medical illness that would require general anaesthesia

\section{Procedure}

The study population would be randomized into two groups based on the methods of simple randomization. Each group had a minimum of 75 parturients.

We will preload the patients in both groups with normal saline solution $500 \mathrm{ml}$ before inducing spinal anaesthesia. The baseline heartrate and blood pressure of the parturients would be measured.

After strict aseptic precautions spinal anaesthesia given with 23 guage spinal needle.

Patients in the fixed dose group will be given $0.5 \% 2 \mathrm{ml}$ hyperbaric bupivacaine in addition to Fentanyl $10 \mathrm{mcg}$, intrathecally. Patients in the adjusted group would be given $0.5 \%$ hyperbaric bupvacaine with a volume based on height and weight adjustment as given by the chart below, along with fentanyl $10 \mathrm{mcg}$.

Parturients would then be assessed for adequacy of anaesthesia based on the dermatological level of loss of cold sensation.

They would also be assessed for side effects like hypotension, bradycardia, nausea and vomiting , requirement for vasopressors, conversion to general anaesthesia etc. Hypotension may be considered when the systolic blood pressure is below $30 \%$ of the baseline value and would be treated with ephedrine in bolus doses of $6 \mathrm{mg}$. Bradycardia would be treated with atropine injection.

After the delivery of the baby, intravenous oxytocin 2.5 unit bolus would be given followed by an infusion of $20 \mathrm{u}$ in $500 \mathrm{ml}$ normal saline. The regression of blockade would also be assessed.

Table 1: Height and Weight Adjustment Chart (Values Are in Millilitres)

\begin{tabular}{|c|c|c|c|c|c|c|c|c|c|}
\hline \multirow{2}{*}{$\begin{array}{l}\text { Patient weight: } \\
\text { kg }\end{array}$} & \multicolumn{9}{|c|}{ Patient height cm } \\
\hline & 140 & 145 & 150 & 155 & 160 & 165 & 170 & 175 & 180 \\
\hline 50 & 1.5 & 1.7 & 1.8 & 1.9 & & & & & \\
\hline 55 & 1.5 & 1.6 & 1.8 & 1.9 & 2.0 & & & & \\
\hline 60 & 1.4 & 1.6 & 1.7 & 1.8 & 2.0 & 2.1 & & & \\
\hline 65 & 1.4 & 1.5 & 1.7 & 1.8 & 1.9 & 2.1 & 2.2 & & \\
\hline 70 & 1.3 & 1.5 & 1.6 & 1.8 & 1.9 & 2.0 & 2.2 & 2.3 & \\
\hline 75 & & 1.4 & 1.6 & 1.7 & 1.9 & 2.0 & 2.1 & 2.3 & 2.4 \\
\hline 80 & & 1.4 & 1.5 & 1.7 & 1.8 & 2.0 & 2.1 & 2.2 & 2.4 \\
\hline 85 & & & 1.5 & 1.6 & 1.8 & 1.9 & 2.1 & 2.2 & 2.3 \\
\hline 90 & & & 1.4 & 1.6 & 1.7 & 1.9 & 2.0 & 2.2 & 2.3 \\
\hline 95 & & & & 1.5 & 1.7 & 1.8 & 2.0 & 2.1 & 2.3 \\
\hline 100 & & & & 1.5 & 1.7 & 1.8 & 1.9 & 2.1 & 2.2 \\
\hline 105 & & & & & 1.6 & 1.7 & 1.9 & 2.0 & 2.2 \\
\hline 110 & & & & & & 1.7 & 1.8 & 2.0 & 2.2 \\
\hline
\end{tabular}

Reference: Harten JM, Boyne I, Hannah P, Varveris D, Brown A. Effect of a height and weight adjusted dose of local anesthetic for spinal anesthetic for elective cesarean section. Anaesthesia.2005;60(4):348-53 


\section{JMSCR Vol||05||Issue||12||Page 32130-32141||December}

\section{Statistical Analysis}

Data will be entered in MS EXCEL and analysed using SPSS 23 software.

Continuous data between the groups will be compared using independent sample t-test or Mann-Whitney U test. Categorical variables will be tested using Chi square/Fisher`s exact test. For all test $\mathrm{P}$ value $<0.05$ is considered as statistically significant.

\section{Observations and Results}

Patients were randomized into two groups and one group received adjusted dose and the other group received fixed dose.

\section{Dose of Bupivacaine}

Table 2: Table comparing the dose of $0.5 \%$ bupivacaine in adjusted and fixed groups

\begin{tabular}{|c|c|c|}
\hline & Fixed & Adjusted \\
\hline Mean & 2.0 & 1.8 \\
\hline SD & 0.0 & 0.1 \\
\hline Median & 2.0 & 1.8 \\
\hline Minimum & 2.0 & 1.6 \\
\hline Maximum & 2.0 & 2.2 \\
\hline $\mathrm{t}=16.24^{* *}, \mathrm{p}=0.000$
\end{tabular}

In the fixed dose group we have given $0.5 \%$ bupivacaine $2.0 \mathrm{ml}$. It was observed that the median dose required in the adjusted group (1.8 $\mathrm{ml}$ ) was significantly lower than the dose of 2.0 $\mathrm{ml}$ given in the fixed group. ( $\mathrm{p}$ value $<0.001$ )

\section{Age}

Table 3: Comparison of Age between the Two Groups

\begin{tabular}{|c|c|c|}
\hline & Fixed & Adjusted \\
\hline Mean & 29.0 & 29.2 \\
\hline SD & 4.9 & 5.5 \\
\hline Median & 29.0 & 29.0 \\
\hline Minimum & 20.0 & 19.0 \\
\hline Maximum & 39.0 & 44.0 \\
\hline
\end{tabular}

Figure 1: Comparison of Dose of Bupivacaine Required In the Two Groups

The average age in the adjusted group was 29.2 with a SD of 5.5 and that in the fixed dose group was 29 with a SD of 4.9. The difference in the age 


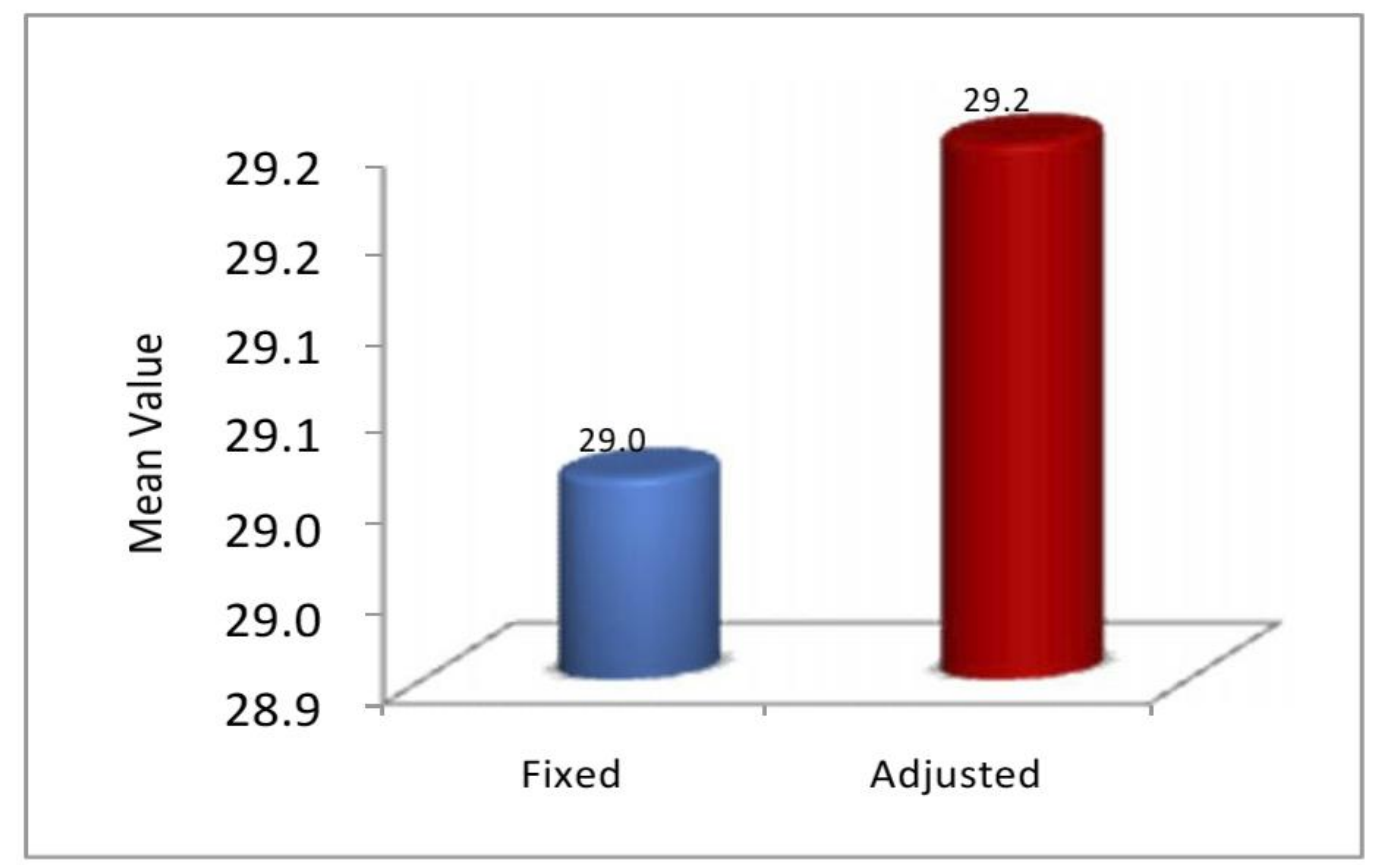

Figure 2: Comparison of Age between the Two Groups

\section{Comparison of Weight and Height}

Table 4: Comparison of Weight between the Two Groups

\begin{tabular}{|c|c|c|}
\hline & Fixed & $\overline{\text { Adjusted }}$ \\
\hline Mean & 67.3 & 66.7 \\
\hline SD & 8.5 & 9.8 \\
\hline Median & 67.0 & 66.0 \\
\hline Minimum & 50.0 & 48.0 \\
\hline Maximum & 88.0 & 95.5 \\
\hline
\end{tabular}

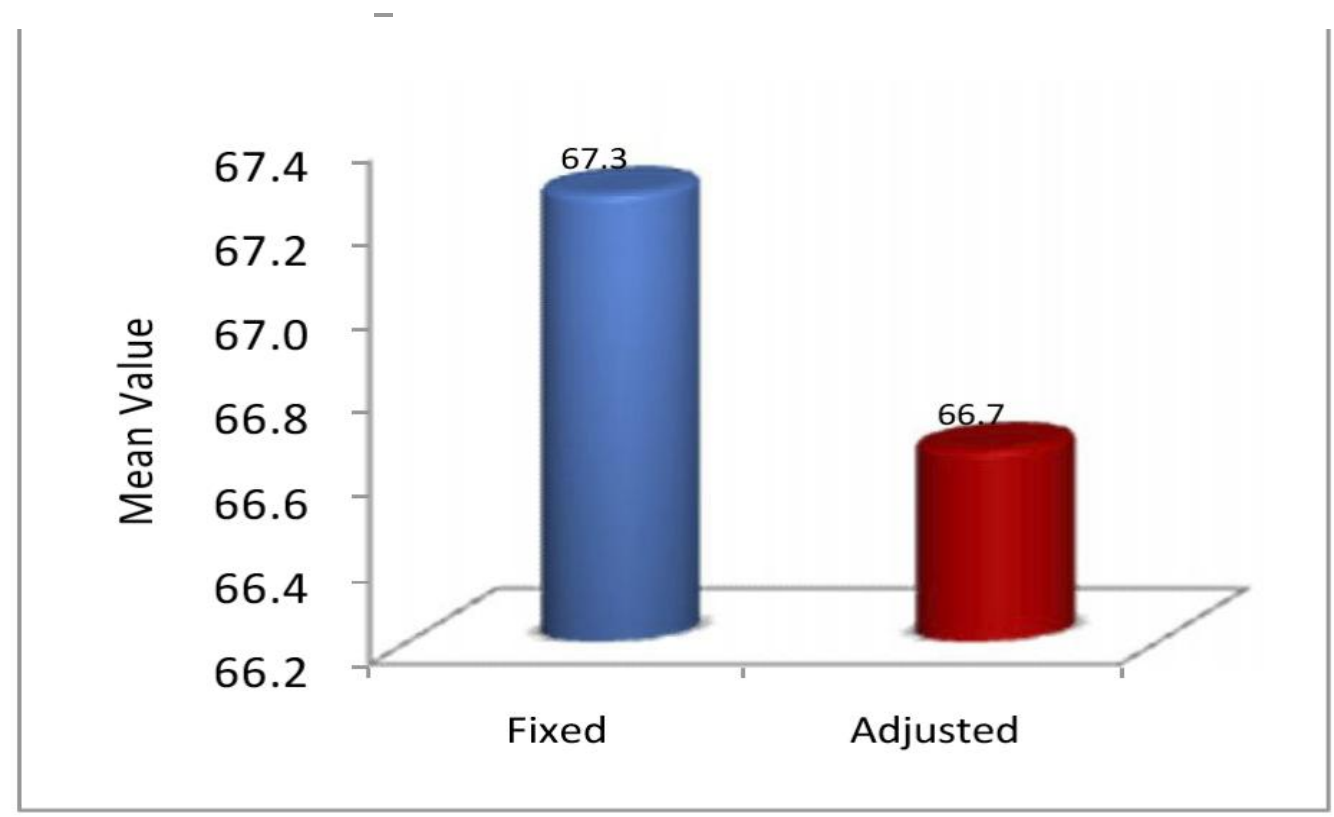

Figure 3: Comparison of Weight between the Two Groups 


\section{JMSCR Vol||05||Issue||12||Page 32130-32141||December}

Table 5: Comparison of Height between the Two Groups

\begin{tabular}{|c|c|c|}
\hline & Fixed & Adjusted \\
\hline Mean & 156.9 & 155.2 \\
\hline SD & 5.3 & 4.7 \\
\hline Median & 157.0 & 155.0 \\
\hline Minimum & 146.0 & 145.0 \\
\hline Maximum & 170.0 & 166.0 \\
\hline
\end{tabular}

The adjusted and the fixed dose groups appear to be similar in terms of the weight and height of the patients, with $\mathrm{p}$ values 0.685 and 0.089 respectively

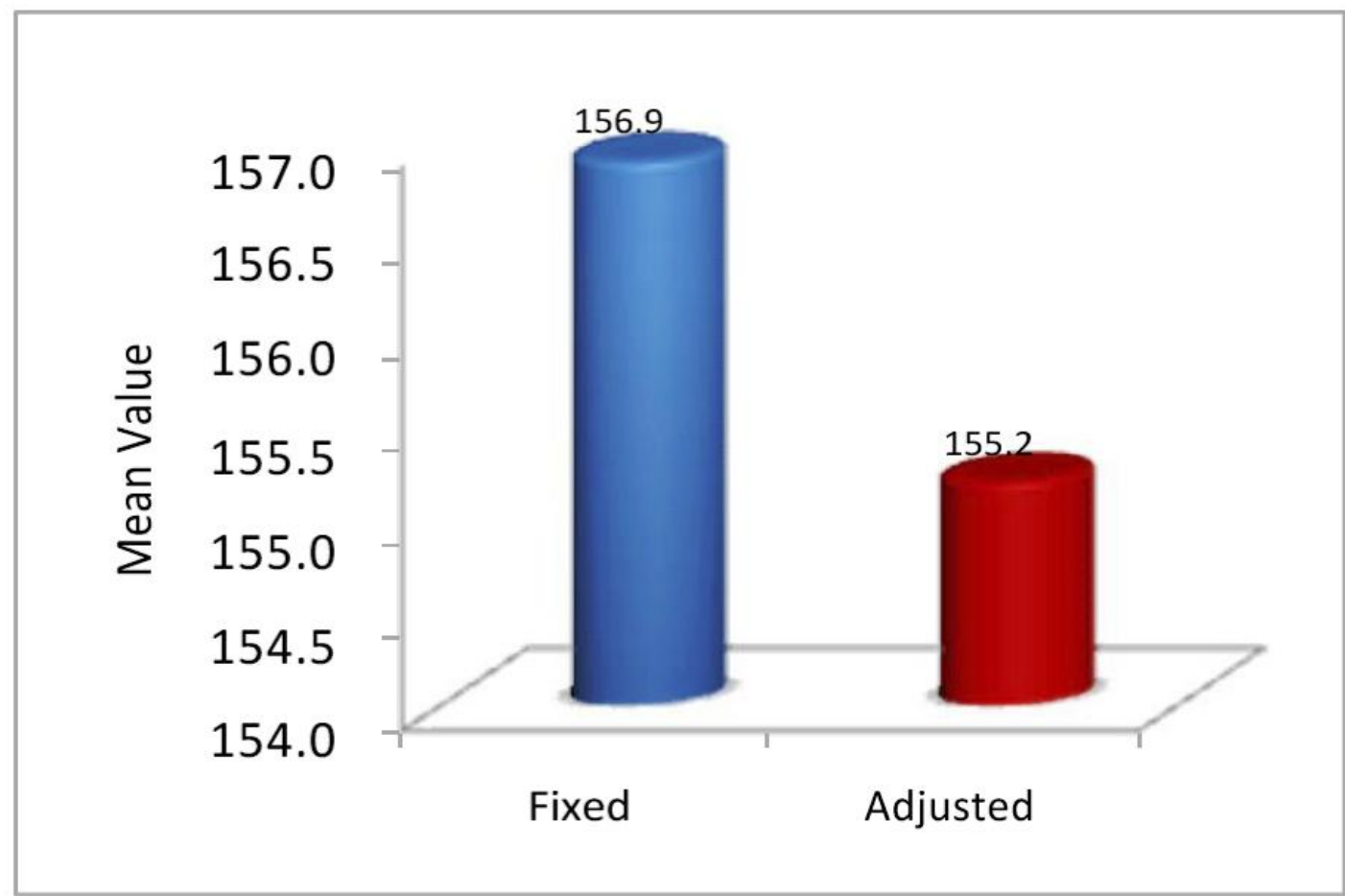

Figure 4: Comparison of Height between the Two Groups

\section{Time to Loss Cold Sensation at T4 Level}

\section{Table 6}

\begin{tabular}{|c|c|c|}
\hline & Adjusted (min) & Fixed (min) \\
\hline Mean \pm SD & $3.1 \pm 1.0$ & $3.2 \pm 1.2$ \\
\hline Median & 1 & 1.2 \\
\hline Inter Quartile range & 0 & 0 \\
\hline Minimum & 3 & 3 \\
\hline Maximum & 6 & 8 \\
\hline
\end{tabular}

There was no statistically significant difference in the time to loss cold sensation at T4 level between the two groups with a $\mathrm{p}$ value of 0.665 


\section{JMSCR Vol||05||Issue||12||Page 32130-32141||December}

\section{Time of Spinal Insertion to Incision}

Table 7: Table Comparison of Time of Insertion of Spinal to Incision

\begin{tabular}{|c|c|c|}
\hline & Fixed & Adjusted \\
\hline Mean & 7.2 & 7.2 \\
\hline SD & 2.5 & 2.2 \\
\hline Median & 8.0 & 7.0 \\
\hline Minimum & 3.0 & 3.0 \\
\hline Maximum & 14.0 & 14.0 \\
\hline
\end{tabular}

There is no statistically significant difference in the time to incision in between the two groups as the $p$ value is 0.972

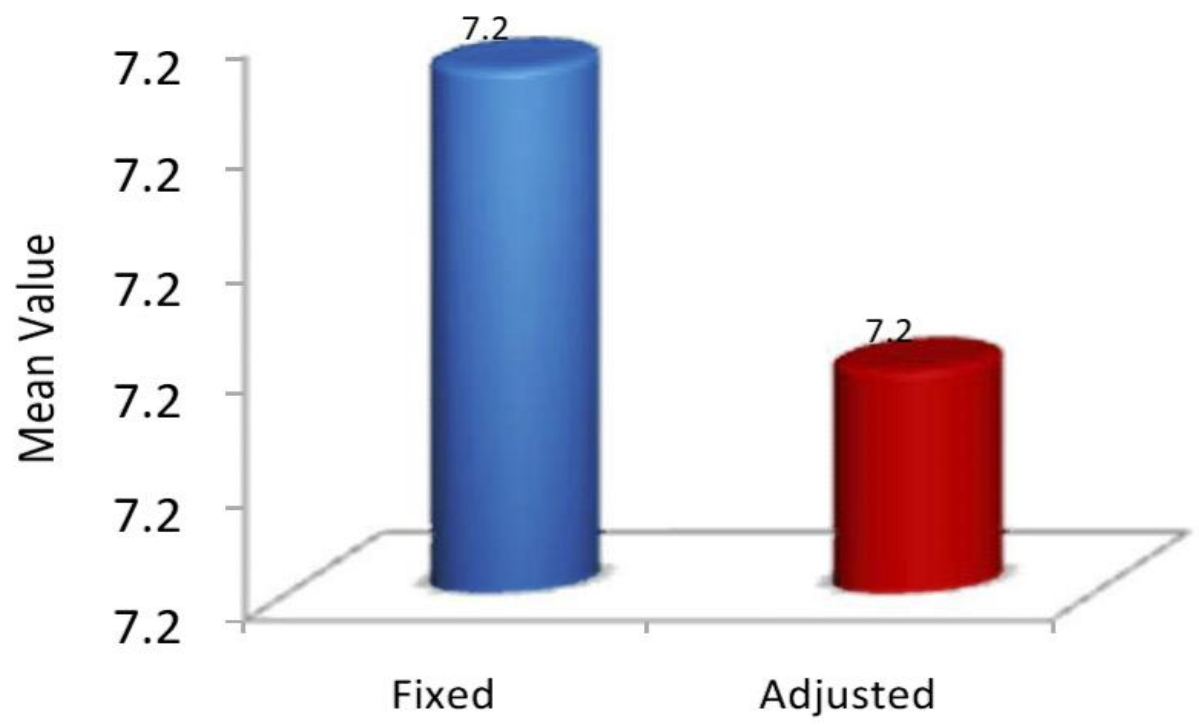

Figure 5: Comparison of Time of Insertion of Spinal to Incision

\section{Hypotension}

Table 8: Comparison of Hypotension between the Two Groups

\begin{tabular}{|c|c|c|c|c|c|c|}
\hline \multirow{2}{*}{ Hypotension } & \multicolumn{2}{|c|}{ Fixed } & \multicolumn{2}{|c|}{ Adjusted } & \multirow{2}{*}{$\square^{2}$} & $\mathrm{p}$ \\
\cline { 2 - 5 } & Count & Percent & Count & Percent & & \\
\hline Yes & 38 & 50.7 & 23 & 30.7 & \multirow{2}{*}{$6.22 *$} & 0.013 \\
\hline No & 37 & 49.3 & 52 & 69.3 & & \\
\hline
\end{tabular}

*: - Significant at 0.05 level

It was observed that the incidence of hypotension was significantly higher in the fixed dose group (50.7\%) compared to the adjusted dose group (30.7\%) ( $\mathrm{p}$ value 0.013 ) 


\section{JMSCR Vol||05||Issue||12||Page 32130-32141||December}

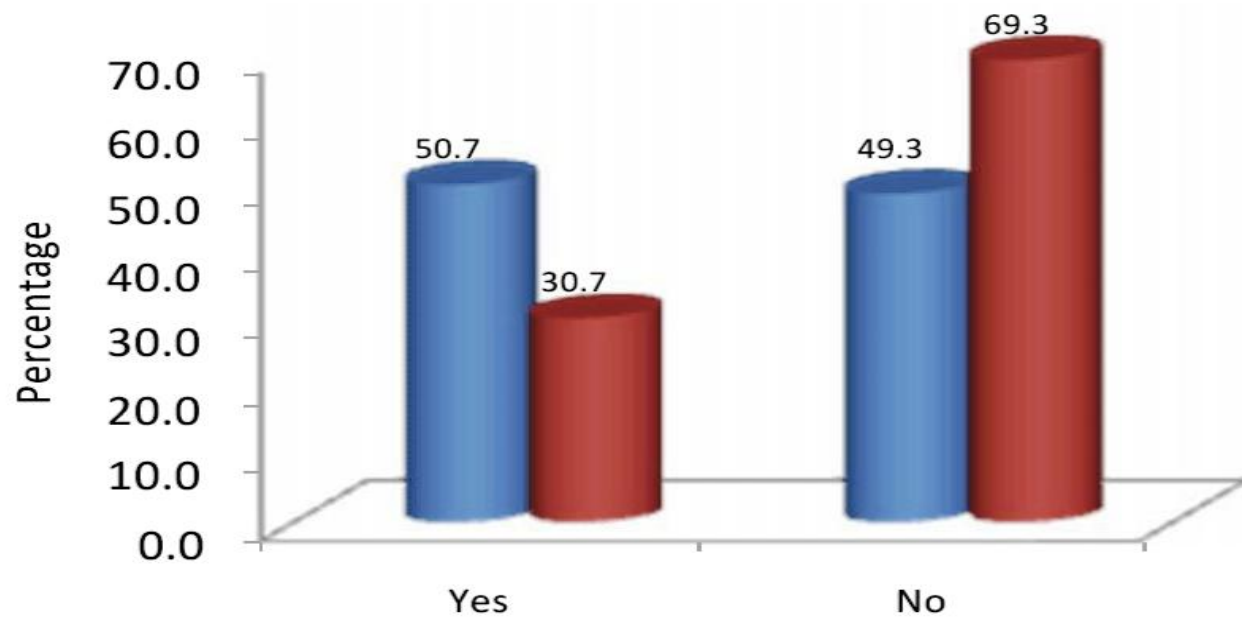

Fixed Adjusted

Figure 6: Comparison of Incidence of Hypotension between the Two Groups

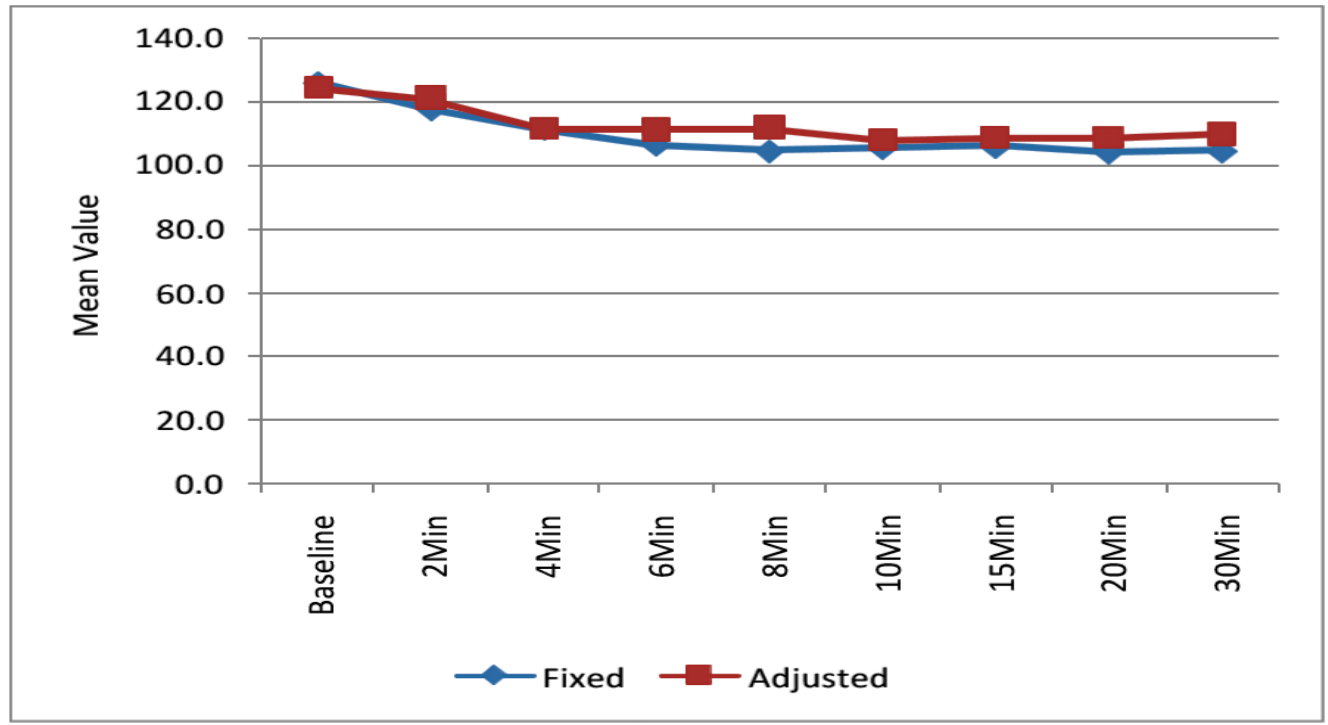

Figure 7: Comparison of SBP at Different Intervals of Time

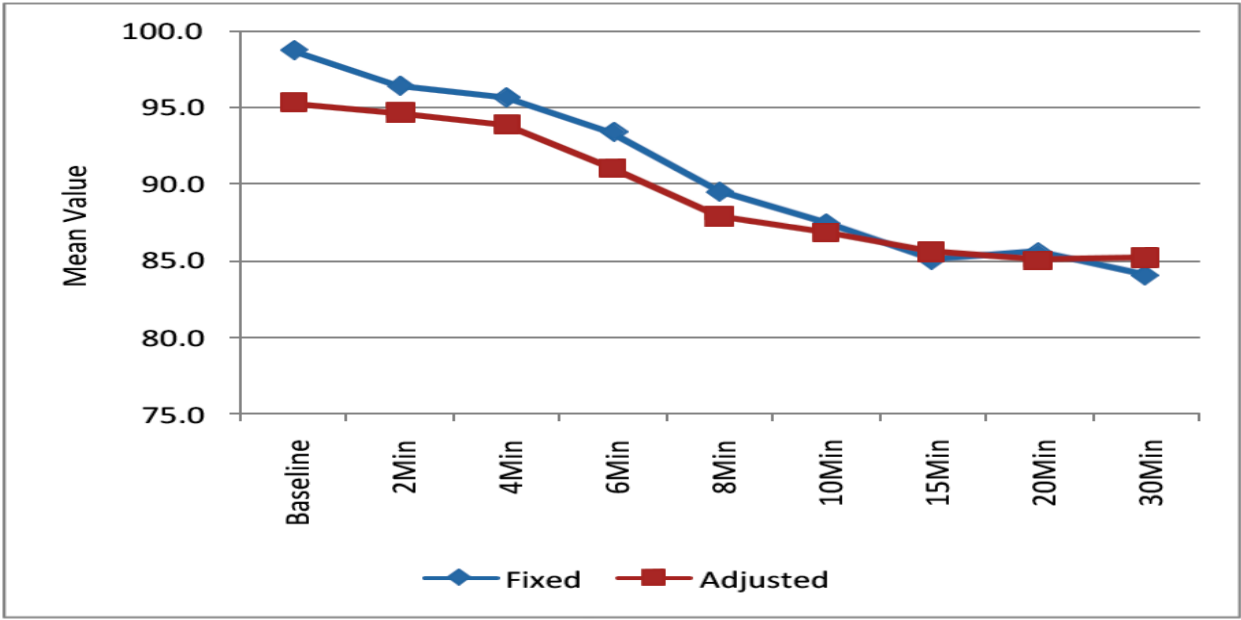

Figure 8 : Comparison of HR at Different Intervals of Time 


\section{JMSCR Vol||05||Issue||12||Page 32130-32141||December}

\section{Ephedrine Given}

Table 9: Comparison of Ephedrine Given In the Two Groups

\begin{tabular}{|c|c|c|c|c|c|c|}
\hline \multirow{2}{*}{ Ephedrine Given } & \multicolumn{2}{|c|}{ Fixed } & \multicolumn{2}{|c|}{ Adjusted } & \multirow{2}{*}{$\square^{2}$} & \multirow{2}{*}{$\mathrm{P}$} \\
\cline { 2 - 5 } & Count & Percent & Count & Percent & & \\
\hline Yes & 38 & 50.7 & 23 & 30.7 & \multirow{2}{*}{$6.22^{*}$} & \multirow{2}{*}{0.013} \\
\hline No & 37 & 49.3 & 52 & 69.3 & \\
\hline
\end{tabular}

*: - Significant at 0.05 level

Ephedrine was given to $50.7 \%$ of patients in the fixed dose group and $30.7 \%$ of patients in the adjusted dose group. Ephedrine was given to significantly more patients in the fixed dose group than in the adjusted dose group (since ephedrine was given to all patients who developed hypotension table and $\mathrm{p}$ values are the same as that of hypotension)

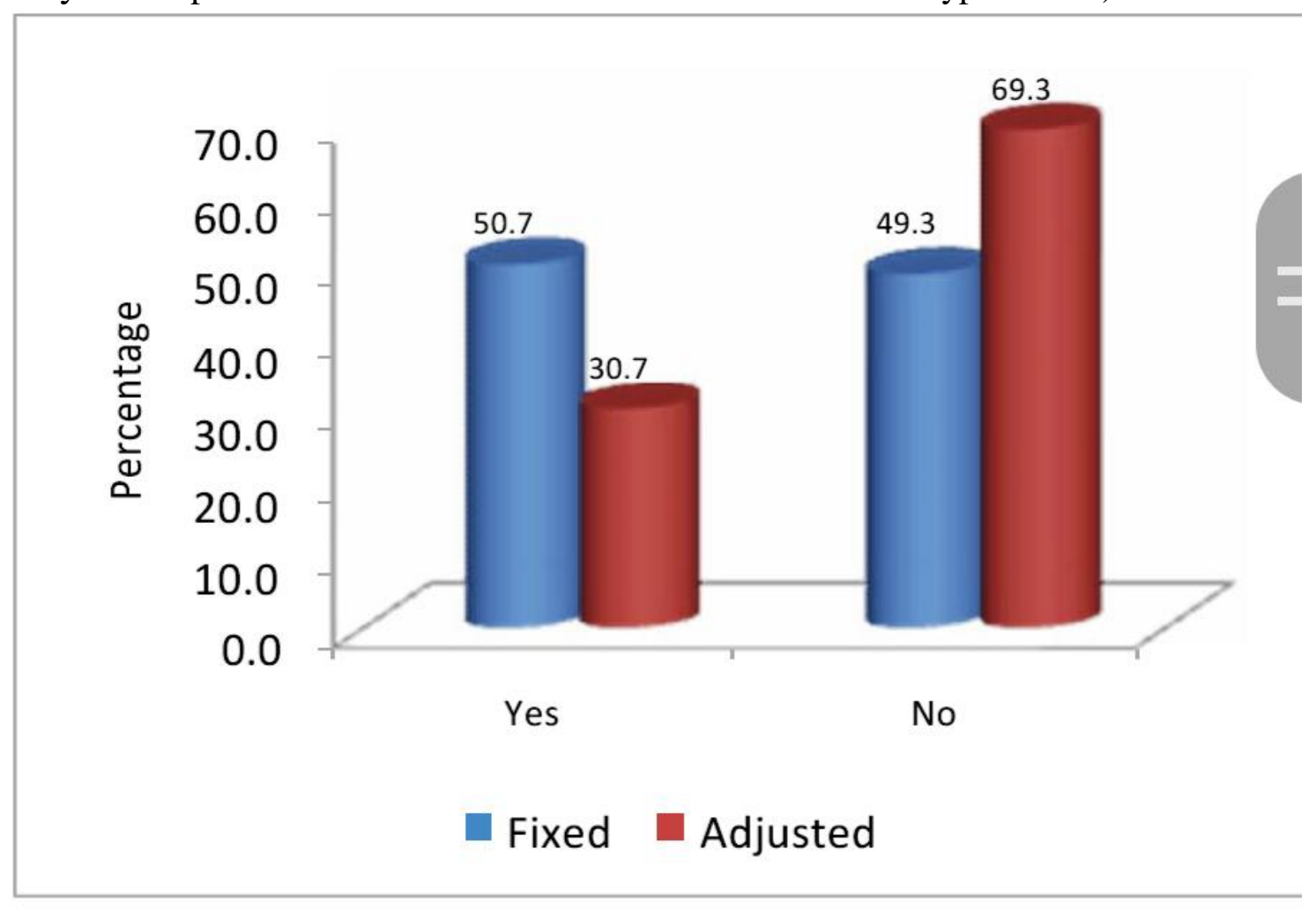

Figure 9: Comparison of Ephedrine Given In the Two Groups

\section{Ephedrine Dose Required}

Table 10: Table Comparison of Ephedrine Dose Required

\begin{tabular}{|c|c|c|}
\hline & Fixed & Adjusted \\
\hline Mean & 8.1 & 7.1 \\
\hline SD & 4.8 & 3.7 \\
\hline Median & 6.0 & 6.0 \\
\hline Minimum & 3.0 & 0.0 \\
\hline Maximum & 24.0 & 18.0 \\
\hline
\end{tabular}

There was statistically no significant difference between the dose of ephedrine given in the fixed dose group and the adjusted dose group. ( $p$ value 0.384 ) Median dose required was $6 \mathrm{mg}$ each in either groups. 


\section{JMSCR Vol||05||Issue||12||Page 32130-32141||December}

\section{Head Down Tilt Required}

Table 11: Comparison of Head Down Tilt

\begin{tabular}{|c|c|c|c|c|c|c|}
\hline \multirow{2}{*}{ Head Down Tilt } & \multicolumn{2}{|c|}{ Fixed } & \multicolumn{2}{|c|}{ Adjusted } & \multirow{2}{*}{ 2 } & \multirow{2}{*}{ P } \\
\cline { 2 - 5 } & Count & Percent & Count & Percent & & \\
\hline Yes & 3 & 4.0 & 5 & 6.7 & \multirow{2}{*}{0.53} & \multirow{2}{*}{0.467} \\
\hline No & 72 & 96.0 & 70 & 93.3 & 0.3 & \\
\hline
\end{tabular}

$4 \%$ of patients in the fixed dose group and $6.7 \%$ difference was found to be statistically not of the patients in the adjusted dose group required head down tilt. With a $\mathrm{p}$ value of 0.467 , the significant.

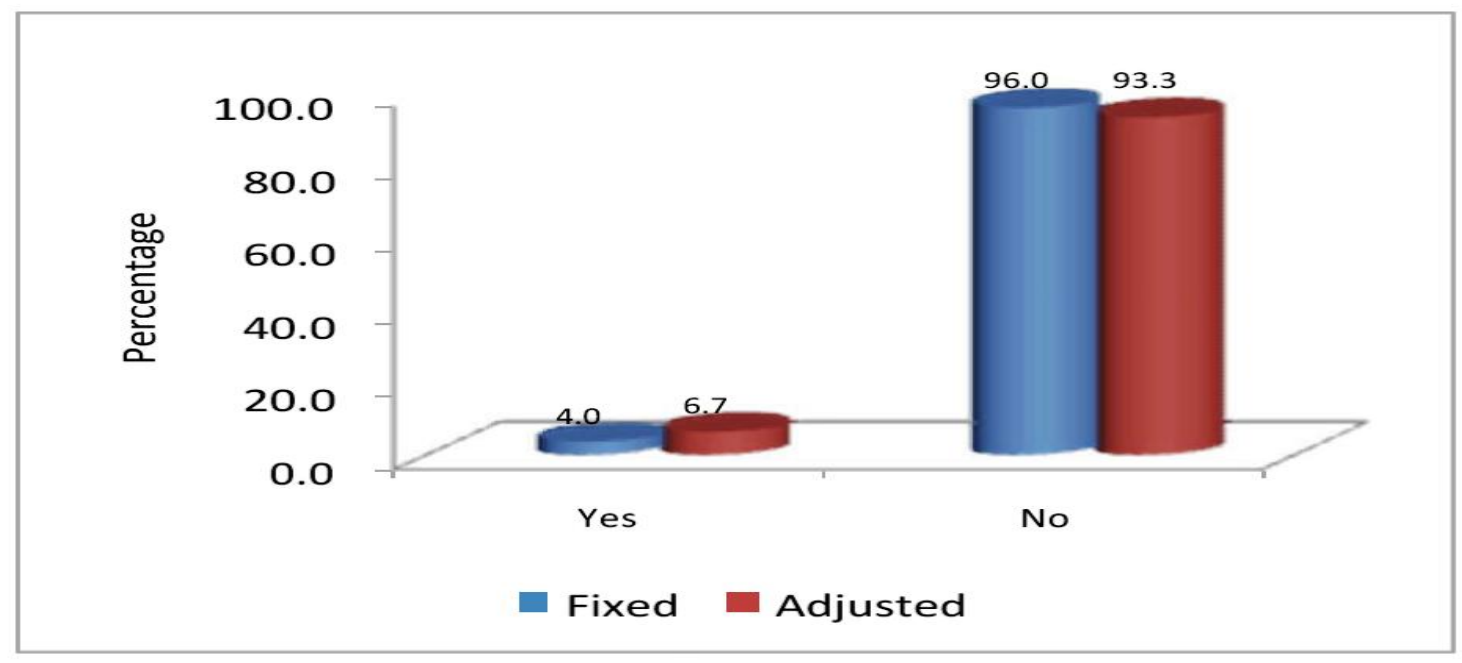

Figure 11: Head Down Tilt Required In between the Groups

\section{Supplementary Analgesia}

Table 12: Comparison of Supplementary Analgesia

\begin{tabular}{|c|c|c|c|c|c|c|}
\hline \multirow{2}{*}{$\begin{array}{c}\text { Supplementary } \\
\text { Analgesia }\end{array}$} & \multicolumn{2}{|c|}{ Fixed } & \multicolumn{2}{|c|}{ Adjusted } & \multirow{2}{*}{$\square^{2}$} & \multirow{2}{*}{$\mathrm{P}$} \\
\cline { 2 - 5 } & Count & Percent & Count & Percent & & \\
\hline Yes & 2 & 2.7 & 2 & 2.7 & & \multirow{2}{*}{0} \\
\hline No & 73 & 97.3 & 73 & 97.3 & 0 & 1.000 \\
\hline
\end{tabular}

$2.7 \%$ of patients in both the groups required supplementary analgesia, the difference was nil between the two groups

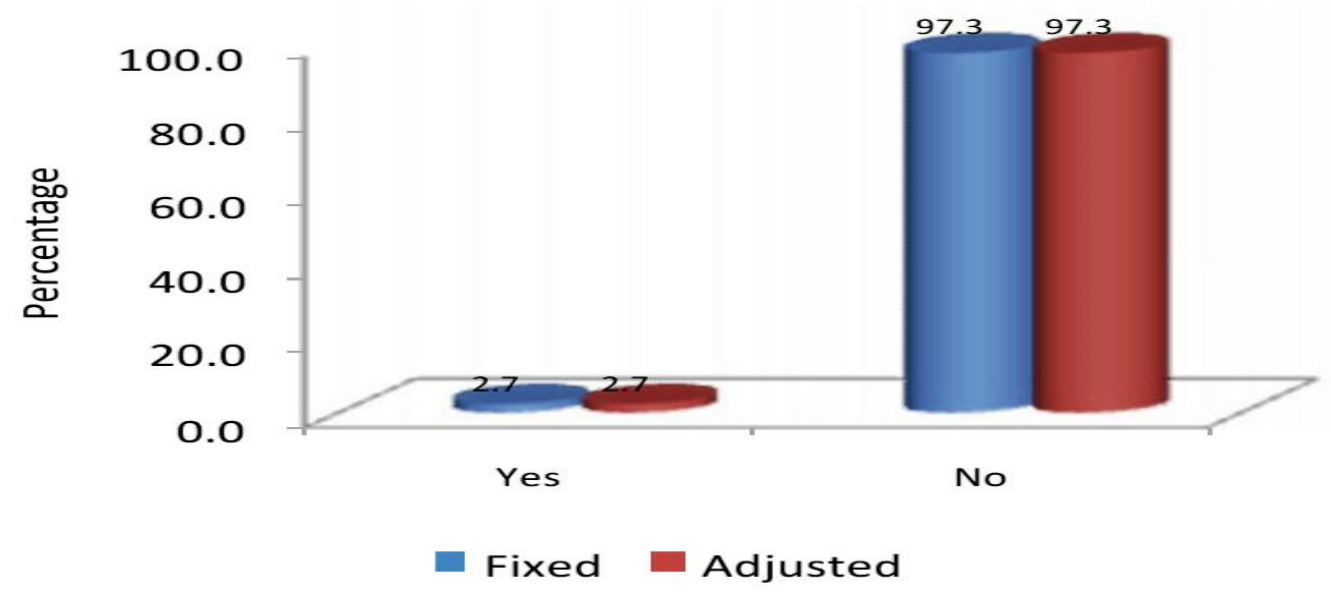

Figure 12: Supplementary Analgesia Requirement between the Two Groups 


\section{JMSCR Vol||05||Issue||12||Page 32130-32141||December}

\section{Conversion To GA}

Table 13: Comparison of Conversion to GA

\begin{tabular}{|c|c|c|c|c|c|c|}
\hline \multirow{2}{*}{ Conversion to GA } & \multicolumn{2}{|c|}{ Fixed } & \multicolumn{2}{|c|}{ Adjusted } & \multirow{2}{*}{. 2 } & $\mathrm{p}$ \\
\cline { 2 - 5 } & Count & Percent & Count & Percent & & \\
\hline Yes & 0 & 0.0 & 0 & 0.0 & \multirow{2}{*}{-} & - \\
\hline No & 75 & 100.0 & 75 & 100.0 & & \\
\hline
\end{tabular}

There was no incidence of conversion to GA in either of the groups.

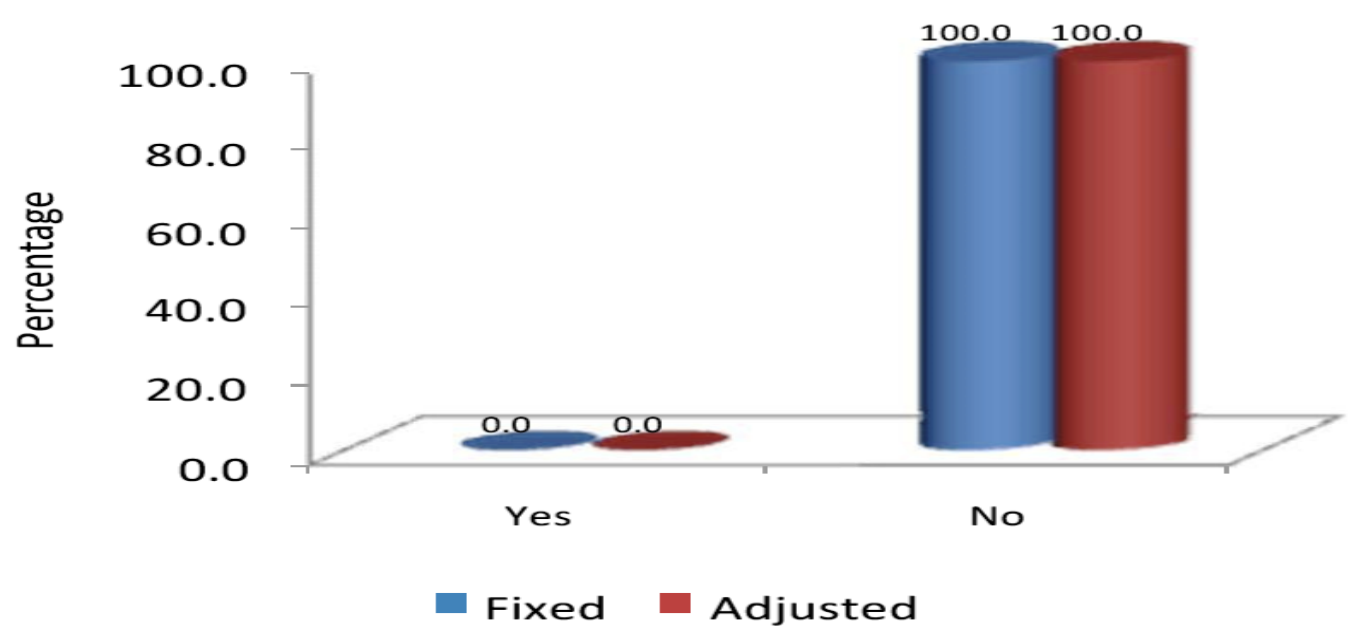

Fig 13: Comparison of Conversion to GA

\section{Nausea and Vomiting}

Table 14: Comparison of Nausea/Vomiting

\begin{tabular}{|c|c|c|c|c|c|c|}
\hline \multirow{2}{*}{ Nausea/Vomiting } & \multicolumn{2}{|c|}{ Fixed } & \multicolumn{2}{|c|}{ Adjusted } & \multirow{2}{*}{$\square^{2}$} & \multirow{2}{*}{$\mathrm{p}$} \\
\hline & Count & Percent & Count & Percent & & \\
\hline Yes & 3 & 4.0 & 2 & 2.7 & \multirow{2}{*}{0.21} & \multirow{2}{*}{0.649} \\
\hline No & 72 & 96.0 & 73 & 97.3 & & \\
\hline
\end{tabular}

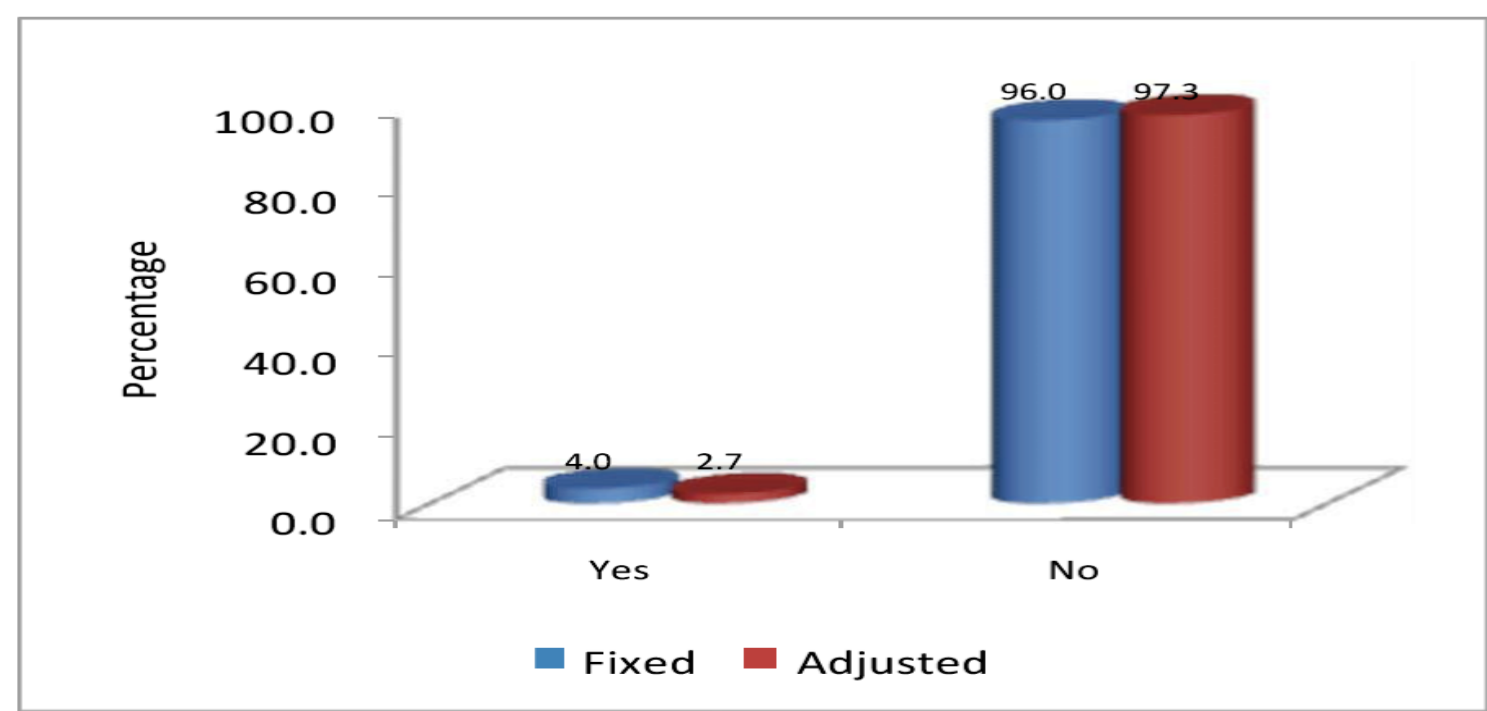

FIG 14: Comparison of Nausea/Vomiting between the Two Groups 


\section{JMSCR Vol||05||Issue||12||Page 32130-32141||December}

\section{Sensory Level At 25 Minutes}

Table 15: Comparison of Sensory Level@25min

\begin{tabular}{|c|c|c|c|c|c|c|}
\hline \multirow{2}{*}{$\begin{array}{c}\text { Sensory } \\
\text { Level@25min }\end{array}$} & \multicolumn{2}{|c|}{ Fixed } & \multicolumn{2}{|c|}{ Adjusted } & \multirow{2}{*}{$\square^{2}$} & \multirow{2}{*}{$\mathrm{P}$} \\
\hline & Count & Percent & Count & Percent & & \\
\hline $\mathrm{T} 4$ & 42 & 56.0 & 4 & 5.3 & \multirow{3}{*}{$53.97 * *$} & \multirow{3}{*}{0.000} \\
\hline T5 & 29 & 38.7 & 40 & 53.3 & & \\
\hline T6 & 4 & 5.3 & 31 & 41.3 & & \\
\hline
\end{tabular}

It was observed that most patients in the fixed dose group (56\%) had their sensory level at T4 level, compared to the adjusted dose group (5.3\%), with a $\mathrm{p}$ value $<0.05$, the difference was found to be statistically significant.

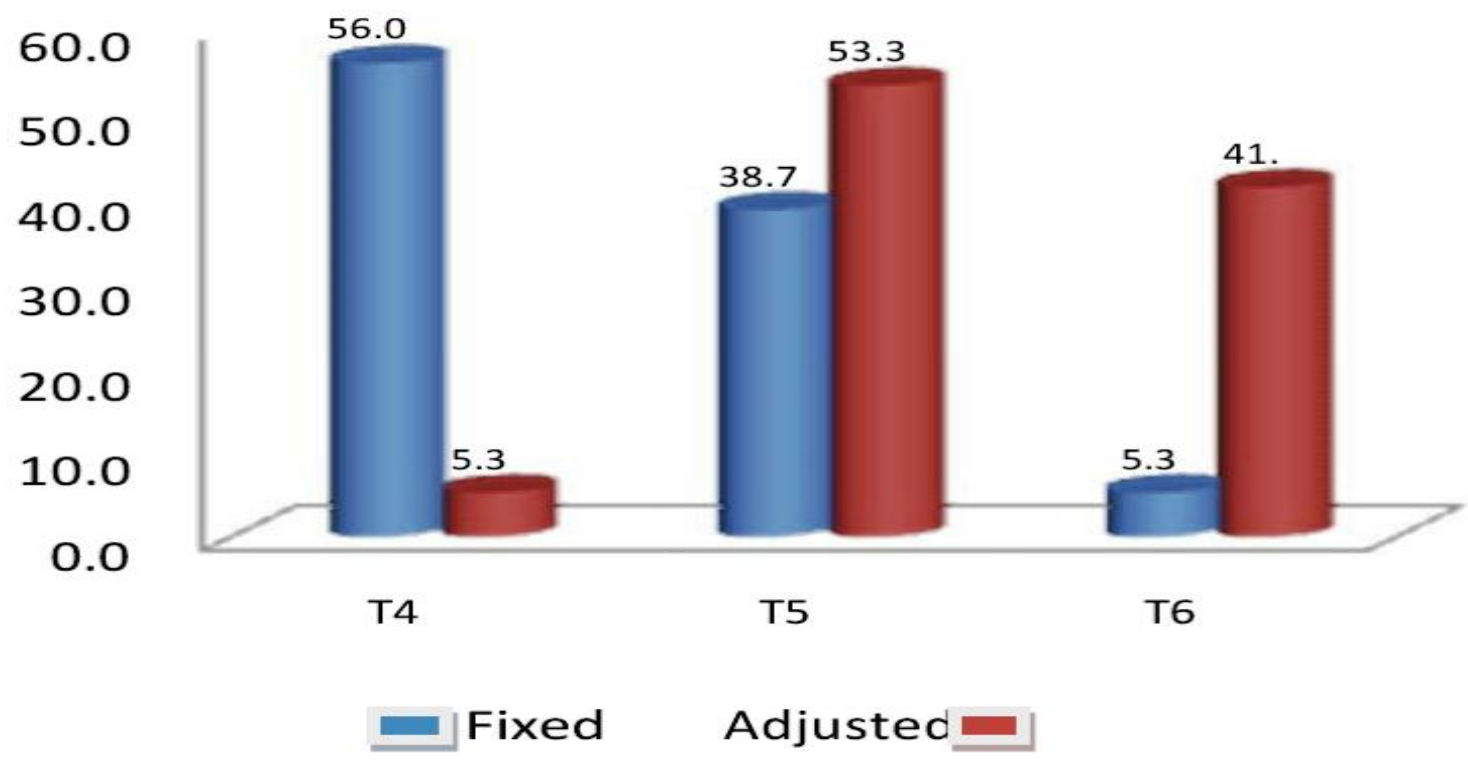

Fig 15

\section{Discussion}

The dose adjustment of intrathecal hyperbaric bupivacaine for caesarean section on the basis of the height and weight of patients significantly reduced bupivacaine requirement and the incidence of hypotension without affecting the efficacy of anaesthesia.

\section{Dose of bupivacaine}

Patients in the adjusted dose group received a median dose of bupivacaine of

$1.8 \mathrm{ml}(9 \mathrm{mg})$, which was significantly smaller than the dose of $2.0 \mathrm{ml}(10 \mathrm{mg})$ administered in the fixed dose group. ( $p$ value $<0.001)$ The lowest dose was $1.6 \mathrm{ml}$ (8mg).

\section{Adequacy of anaesthesia}

Spinal anaesthesia was adequate in the adjusted dose group in almost all patients; two patients $(2.7 \%)$ in either group required supplementary analgesia.

\section{Hypotension}

It was observed in our study that the incidence of hypotension was significantly higher in fixed dose group $(50.7 \%)$ compared to adjusted dose group (30.7\%), which was statistically significant.

\section{Ephedrine requirement and dosage}

In our study, as with hypotension, the number of patients who had received ephedrine was 


\section{JMSCR Vol||05||Issue||12||Page 32130-32141||December}

significantly higher in the fixed dose group $(50.7 \%)$ than in the adjusted dose group $(30.7 \%)$. However, the median dose of ephedrine administered was the same $(6 \mathrm{mg})$ in either group.

\section{Sensory level at 25 minutes}

While a $56 \%$ of patients in the fixed dose group had their sensory level at $\mathrm{T} 4$ at the end of 25 minutes, only $5.3 \%$ of those in the adjusted dose group had their level at T4.

\section{Nausea/vomiting}

There was no significant difference in the number of patients reporting nausea or vomiting.

\section{Regression of block}

It was found that there was no significant difference in the regression of block in between the two groups.

\section{Conclusion}

Height and weight adjusted dose of hyperbaric bupivacaine, significantly reduces the dose requirement compared to a fixed dose protocol without compromising on the efficacy of intraoperative anaesthesia.

The adjusted dose technique significantly reduced the incidence of hypotension and the requirement of ephedrine, in comparison to the fixed dose technique.

The level of spinal block at 25 minutes of administration of spinal anesthetic was significantly lower in the adjusted dose group (below T4) as compared to the fixed dose group (T4).

There were no significant differences between the two groups in the need for supplementary analgesia, head-tilt or conversion to general anesthesia, denoting that the adequacy of intraoperative anesthesia was comparable in both the groups.

There was no significant difference between the two groups in the incidence of nausea or vomiting

\section{References}

1. Harten JM, Boyne I, Hannah P, Varveris D, Brown A. Effect of a height and weight adjusted dose of local anesthetic for spinal anesthetic for elective cesarean section. Anaesthesia.2005;60(4):348-53

2. Chung CJ, Bae SH, Chae KY, Chin YJ. Spinal anaesthesia with $0.25 \%$ hyperbaric bupivacaine for Caesarean section. Effects of volume. British Journal of Anaesthesia. 1996; 77:145-

3. Boyne I, Varveris D, Harten J, Brown A. National survey of dose of hyperbaric bupivacaine for elective caesarean section under spinal anaesthesia. International Journal of Obstetric Anaesthesia.2000; 13: 20.

4. Varveris D, Boyne I, Harten J, Brown A. Graded dosing of subarachnoid bupivacaine by height and weight for elective caesarean section. International Journal of Obstetric Anaesthesia.2000; 13: 20. 